\title{
O SUJEITO ÉTICO: QUE SE CUIDA E SE SABE
}

\author{
Robson Wander C. LOPES ${ }^{1}$
}

\section{Resumo}

Este artigo tematiza o sujeito ético em "tempos sombrios", isto é, refere-se ao sujeito existente no momento histórico em que as referências dos códigos morais se ausentam e tendem a não mais contribuir com a constituição ontológica do sujeito. O objetivo é analisar a construção do sujeito ético enquanto subjetivação, com base na filosofia de Michel Foucault. A metodologia é de natureza bibliográfica, trata-se de uma pesquisa de abordagem analítica desenvolvendo o estudo em seus dois eixos temáticos: a compreensão e a interpretação de alguns dos textos do "último Foucault" (1979-1984). Diante da ausência das referências morais no tempo presente, importa buscar nos enunciados discursivos e históricos, os elementos constitutivos do sujeito e as práticas de si, como formas a responderem ao "cuidado de si" que antecede e define o "conhecimento de si" possibilitando o sujeito criar-se, mesmo com a ausência de referência de códigos morais.

Palavras-chave: Sujeito. Verdade. Cuidado de si.

\begin{abstract}
This article thematizes the ethical subject in "dark times," that is, it refers to the subject existing in the historical moment in which the references of moral codes are absent and tend not to contribute to the ontological constitution of the subject. The objective is to analyze the construction of the ethical subject as subjectivation, based on the philosophy of Michel Foucault. The methodology is of a bibliographic nature, it is a research of analytical approach developing the study in its two thematic axes: the understanding and the interpretation of some of the texts of the "last Foucault" (1979-1984). Faced with the absence of moral references in the present time, it is important to seek in the discursive and historical statements, the constitutive elements of the subject and the practices of oneself, as ways of responding to the "self-care" that precedes and defines "self-knowledge" the subject to create, even with the absence of reference of moral codes.
\end{abstract}

Keywords: Subject. Truth. Care for yourself.

\section{INTRODUÇÃO}

Ao depararmo-nos com as trevas de nosso tempo ou com os "tempos sombrios" da primeira metade do século passado, como propunha Arendt (2008), a reflexão acerca da moralidade, da ética e do sujeito moral necessita de revisões. Sem a pretensão de levar à exaustão essa temática, tampouco de abarcar a totalidade das questões que a norteiam, a proposta é pô-la em debate considerando como contexto, ainda que posta em suspenso neste trabalho, a atual realidade ético-política que experimentamos na sociedade brasileira: insegurança social, ausência de referenciais éticos e códigos morais confiáveis, agravamento da corrupção política, dentre outras implicações na formação do sujeito.

\footnotetext{
${ }^{1}$ Mestre em Ciências da Religião (UEPA). Docente do Instituto de Educação, Ciência e Tecnologia do Pará / Campus Belém. E-mail: robson.lopes@ifpa.edu.br.
} 
É nesse bojo que nossa problemática se articula ao propor o tema da noção de sujeito ético como um processo pendular entre a exterioridade da história e da cultura e a interioridade da subjetividade. Dito de outra maneira: a realidade sócio-política atual apresenta uma tendência em produzir um sujeito obscuro, sombrio, sufocado por um niilismo ético ${ }^{2}$, isto é, pela ausência de códigos morais em suas estruturas culturais e históricas, que por sua vez, em sua interioridade, tende a abandonar-se numa espécie de individualismo autista $^{3}$ que, embora busque relações com os outros, fecha-se e esconde-se de si mesmo, e sua relação com a verdade é ilusória, mascarada, ignorada.

Não faremos um estudo conjuntural acerca das problemáticas sócio-políticas atuais do país, nem propomos uma análise do sujeito ético imbricado na complexidade que o dispõe na sociedade brasileira. Aqui não é o espaço adequado para isso. O recorte da reflexão é bem mais simples. Apenas apresentamos, de maneira bastante introdutória, uma reflexão que poderá contribuir nas discussões que retomam tais implicações na relação ética-política do sujeito enquanto agente moral, sem nenhuma intenção a priori dos resultados desta reflexão.

O foco será a formação do sujeito ético situado em "tempos sombrios" que o envolve mediante a possibilidade de esse sujeito construir-se eticamente. Assim, o objetivo, finalmente, é pôr em questão o processo de subjetivação provocando o diálogo com base na reflexão genealógica de Michel Foucault. Abordaremos a filosofia foucaultiana em seu último ciclo, que comumente se chama de "último Foucault" ou "Ciclo ético". Ao referirmo-nos ao ciclo ético, entendemos o conjunto de obras desse filósofo, quais sejam: cursos, livros e Ditos e escritos (conferências, palestras, entrevistas...), ministrados e ou produzidos pelo filósofo francês, entre os anos de 1979 a $1984^{4}$.

\footnotetext{
${ }^{2} \mathrm{O}$ nosso entendimento acerca do niilismo ético segue a compreensão apresentada por Oliveira (2015), cujas ideias de bem e de mal perdem seus valores e os valores morais tornam-se inconsistentes.

${ }^{3}$ Por individualismo autista, com base em Bauman (2001), entendemos como o modo pelo qual o sujeito moderno tornou-se líquido, fluído, omisso da responsabilidade de suas decisões, ações e desejos, abstendo-se dos valores dos fins, mas buscando as ações em si mesmas, com a tendência de viver abscôndito de si, sobretudo dos outros, numa interioridade que busca exercer sua intersubjetividade indiretamente através das mídias.

${ }^{4}$ É possível obter uma visão geral da produção teórica de Michel Foucault através das indicações bibliográficas organizadas por Bert (2013) e Castro (2014).
} 


\section{O SUJEITO OBSCURO: ENTRE O NIILISMO ÉTICO E O INDIVIDUALISMO}

\section{AUTISTA}

Partirmos do pressuposto que a interioridade do sujeito ético depende, em grande escala, do que se define pela exterioridade de si, nas relações com os outros, com a comunidade ética, no desenrolar da história e da cultura (FOUCAULT, 1993; 2001) ${ }^{5}$. Se o sujeito ético não é uma categoria da interioridade universal, mas, singular e histórico, e, por outro lado, o nosso tempo está mais que sombrio, está em profundas trevas a envolver tal sujeito histórico e cultural, então podemos coligir que a fisionomia do sujeito, neste momento histórico, é um sujeito sombrio, no mínimo obscuro. O que mais poderíamos delinear como sendo a substância da exterioridade do sujeito ético, se não as instituições sociais responsáveis pela seguridade ético-político do cidadão numa pretensa democracia?

O fato é que as principais instituições ${ }^{6}$ da infante democracia brasileira encontram-se num descrédito crescente, causando assim um desbaratamento da formação do sujeito que vive neste momento histórico. Dessa feita, o que se observa, em grande margem, são cidadãos perdidos em meio ao marasmo de imoralidades, desonestidades, injustiças, impunidades e corrupções. Sujeitos sem referências de padrões morais palpáveis, uma lacuna de códigos morais.

Em 1968, Hannah Arendt, em seu livro "Men in dark times" (Homens em tempos sombrios), ao apresentar as "sombras" da primeira metade do século XX, aponta os "desastres morais" como uma das realidades compartilhadas por diversas personagens estudadas em seus ensaios, dentre as quais, por exemplo, Rosa Luxemburgo (1871-1919); Angelo Giuseppe Roncalli (Papa de 1958 a 1963); Walter Benjamin (1892-1940); Bertolt Brecht (1898-1956). Estamos há meio século da publicação da obra, mas tudo indica que os "tempos sombrios", com seus "desastres morais" não deram, e não darão tão cedo, lugar à luz do bom senso, pelo contrário, afogam o sujeito num niilismo ético que torna os juízos de valores sem

\footnotetext{
${ }^{5}$ Com relação ao sujeito constituído pela história e pela cultura, diz Foucault (1993, p. 205): "esforcei-me por sair da filosofia do sujeito por meio de uma genealogia que estuda a constituição do sujeito através da história"; e noutro texto diz o mesmo autor: "esforcei-me por sair da filosofia do sujeito por meio de uma genealogia do sujeito moderno, que eu abordo como uma realidade histórica e cultural; ou seja, como alguma coisa que é suscetível de se transformar" (FOUCAULT, 2001, p. 989).

${ }^{6}$ O jornal O Liberal (2018), com base em pesquisa do Datafolha, noticiou que a instituição da Presidência da República, na pessoa do Presidente, chegou a 70\% de reprovação popular. Datafolha (2017) afirma que 92\% acreditam que Justiça trata melhor os ricos do que os pobres, causando insegurança e desconfiança na opinião pública. E segundo o Jornal O Estado de São Paulo (CHADE, 2013), para 81\%, os Partidos políticos são "corruptos ou muito corruptos".
} 
consistências e sem nenhuma finalidade de orientações para a ação do sujeito (OLIVEIRA, 2015, p. 821).

Além da expressão "tempos sombrios" que aqui nos apropriamos para indicar uma realidade ético-política de nosso próprio tempo, também consideramos o que, na mesma obra, Arendt entende por "camuflagem", que emerge do próprio "sistema" e que significa dizer que, apesar de a realidade se mostrar cruel e injusta, e sem nenhum mistério, nem todos os sujeitos conseguem visualizá-la, em absoluto.

Zingmunt Bauman publicou algo que nos interessa, não só na explanação do estado da questão, mas na delimitação da problemática que se pretende discutir neste artigo. Fazemos referência a duas obras desse autor. A primeira, publicada em 1993, sob o título Postmodern Ethics (Ética pós-moderna), buscou apresentar um "estudo de ética moderna" indicando a “[...] oportunidade ao sociólogo crítico" (BAUMAN, 1997, p.7) a perceber que a

modernidade tem a estranha capacidade de frustrar a auto-análise (sic), ela embrulhou os mecanismos de auto-reprodução (sic) com o véu de ilusões sem o qual esses mecanismos, sendo que são, não podiam funcionar adequadamente [...] (Idem Ibidem, p. 8, e grifos nossos).

O que colocamos em evidência, apoiados por Bauman, é a frustração do sujeito moral em não poder produzir seus inventários morais; ou em se tornar sujeitos do tipo moderno, que segundo o autor, são um mesclado de "vagabundo-turista": um errante sem destino destituído de espaçamento moral, e de férias, a apreciar o constante desmantelamento do Estado de Bem-Estar Social. O autor desenvolve sua hipótese demonstrando que não é realizável, ou pelo menos, inencontrável o lugar de uma liberdade absoluta, ou de uma dependência absoluta dos valores morais e das referências para as ações éticas, que num mundo das escolhas individuais, tais pressupostos tornaram-se relativos ao ponto de impossibilitar juízos morais absolutos. Portanto, a modernidade falhou em sua pretensão de rasgar a "máscara das ilusões".

Em outra obra do mesmo autor, "Community: Seeking Safety in na Insecure" (Comunidade: a busca por segurança no mundo atual), Bauman (2003) analisa, com o recurso metafórico do mito de Tântalo, que a realidade de uma "comunidade não está ao nosso alcance", uma vez que o dilema da "tensão entre a segurança e a liberdade e, portanto, entre a comunidade e a individualidade, provavelmente nunca será resolvida", porque emerge ao 
sujeito ético as questões de fundo: Como ser livre sem segurança? E como ter segurança sem perder a liberdade? Nesse sentido, diz Bauman:

\footnotetext{
Não seremos humanos sem segurança ou sem liberdade; mas não podemos ter as duas ao mesmo tempo e ambas na quantidade que quisermos. Isso não é razão para que deixemos de tentar [...]" buscar achar a solução e continuar tentando, porque "sendo humanos, não podemos realizar a esperança, nem deixar de tê-la. (Idem Ibidem, p. 11).
}

Com as reflexões do sociólogo em pauta, podemos inferir duas ideias chaves para a composição do estado da questão: a primeira é que, o sujeito ético moderno tornou-se liquefeito, desnorteado, sem rumo e sem destino, não se projeta na existência, um "vagabundo", um "turista"; a segunda é que o sujeito não consegue romper com a "máscara das ilusões" modernas e engana-se com sua autoanálise, não se conhece e não se cuida enquanto sujeito.

Ao tirarmos proveito das contribuições de Arendt e Bauman, podemos ajustar o pensamento da seguinte forma: se para Arendt o sujeito em sua interioridade não consegue perceber as "camuflagens do sistema", para Bauman, o sujeito moderno permanece sem a possibilidade de autoanálise, isso é o que vêm a ser o individualismo autista, um sujeito sombrio, que não se cuida e nem se conhece, cuja ilusão acredita poder ser livre sem a segurança dos outros. Se para Arendt, o sujeito em sua exterioridade depara-se com uma realidade sócio-política que não oferece um código moral seguro, pelo contrário, provoca um "desastre moral", para Bauman, a modernidade fabricou uma exterioridade que causa tensões ao sujeito, colocando-o entre a liberdade e a segurança e tornando-o um "vagabundo sem destino" e ao mesmo tempo um "turista de férias" sem lugar moral que o fixe. Ao que chamamos de niilismo ético, a constituição liquida da exterioridade do sujeito que não faz referências a valores morais em absoluto.

Assim, a problemática que ora apresentamos, bifurca-se em duas vias de análise: por um lado o sujeito ético entendido em sua exterioridade, isto é, compreendido enquanto relação com os códigos morais cujo desafio está em identificar tais códigos num tempo que anuncia sua "ausência", sua "fluidez", seu "desastre", um niilismo ético; por outro lado, o sujeito entendido enquanto interioridade, enquanto subjetividade, na relação de si para si, como individualidade egoica, escondendo-se de si através de "camuflagens" e de "máscaras de ilusões", de individualismo autista. 
Michel Foucault, por sua vez, também identifica no sujeito moderno, com base na genealogia e na hermenêutica do sujeito ocidental, uma "ausência de moral" (FOUCAULT, 1984). E, portanto, a partir desta problemática acerca da definição do sujeito ético em nosso tempo, que organizamos a metodologia desta pesquisa de revisão teórica, no intuito de melhor compreendermo-nos enquanto sujeitos, sujeitos éticos. Diante dessas realidades éticas do niilismo ético e do individualismo autista, o sujeito ético poderá subsistir?

\section{O “CUIDADO DE SI": DO SOMBRIO AO ÉTICO}

Michel Foucault afirma que é no início da idade moderna que ocorre aquilo que ele chama de o "momento cartesiano". Segundo o autor, foi nesse momento que o gnôthi seautón (conhece-te a ti mesmo) foi requalificado e, recebendo uma ênfase e uma atenção jamais dada aos modos pelos quais o sujeito alcança a verdade apenas pelo conhecimento. Ao mesmo tempo ocorreu uma desqualificação do princípio do epiméleia heautoû (cuidado de si) sendo renegado pela laicização do sujeito do conhecimento em detrimento do exílio da espiritualidade como sendo um fenômeno estrito das cercanias clericais e religiosas. Foucault afirma que a "idade moderna da história da verdade começa no momento em que o que permite acender ao verdadeiro é o próprio conhecimento e somente ele”. (FOUCAULT, 2010, p. 18).

O filósofo francês empenha-se em propor a retomada da recriação do sujeito por si mesmo, ao que chamará de estética da existência, ou simplesmente, subjetivação:

\footnotetext{
E se eu sei me interessar pela Antiguidade, é que, por toda uma série de razões a ideia de uma moral como obediência a um código de regras está em processo, presentemente, de desaparecimento; já desapareceu. E à essa ausência de moral, responde, deve responder, uma busca de uma estética da existência. (FOUCAULT, 1984, grifos nossos).
}

Essa necessidade de retomada do sujeito ético, aquele que se cuida através das práticas de si, surge quando a representação de um sujeito se perdeu em meio às tarefas do sujeito do conhecimento, e assim, por conseguinte, o seu acesso à verdade, causando a "ausência de referenciais morais para a constituição do sujeito ético.

Portanto, sobre a estética da existência - ou "artes da existência", diz Foucault: 
Deve-se entende, com isso, práticas refletidas e voluntárias através das quais os homens não somente se fixam regras de conduta, como também procuram se transformar, modificar-se em seu ser singular e fazer de sua vida uma obra que seja portadoras de certos valores estéticos e responda a certos critérios de estilo" (FOUCAULT, 2014c, p. 16).

Ocupar-se de si é, também, além de uma obra de arte, um exercício espiritual. E fazendo uma dialética entre a "espiritualidade" e o "conhecimento" desenvolvidos no Ocidente, Foucault analisa que para os antigos o sujeito não poderia alcançar a verdade, apenas com os exercícios do conhecimento, mas precisava, também e, sobretudo, de ocuparse consigo mesmo, numa constante espiritualidade. Surge, pois, a necessidade de se compreender a "técnica" da espiritualidade enquanto ascética, cujo desenvolvimento se atribui ao princípio do cuidado de si e reformula o princípio do conhece-te a ti mesmo.

A recriação - ou a criação mesmo, como quem cria uma obra de arte - do sujeito por si mesmo, para Foucault, tem, se não a sua origem, mas o seu apogeu no período Imperial, entre a antiguidade grega e o início do cristianismo, quando se evidenciam técnicas que constituem uma verdadeira "cultura de si", de fato, uma "arte da existência" (tecchne tou biou), embora se limitasse na maioria das vezes em um modo privilegiado de indivíduos das classes mais abastardas (FOUCAULT, 2014b, p. 58) ${ }^{7}$.

Foucault (2010, p. 3-19), ao longo de sua aula de 6 de janeiro de 1982, no College de France, faz uma exaustiva fundamentação entre a relação da máxima grega "cuidado de si" (epiméleia heautoû) e a famosa prescrição délfica "conhece-te a ti mesmo" (gnôthi seautón). $\mathrm{O}$ autor sustenta que a primeira, além de mais antiga entre os gregos, orienta a compreensão sobre a segunda, porque o conhecimento de si não deixa de ser uma ocupação consigo, um cuidado consigo. E conclui:

Enfim, com a noção de epiméleia heautoû, temos um corpus definindo uma maneira de ser, uma atitude, formas de reflexão, práticas que constituem uma espécie de fenômeno extremamente importante, não somente na história das representações [...], mas na própria história da subjetividade ou, se quisermos, na história das práticas da subjetividade. (Idem Ibidem, p. 12).

O conhecimento de si, sob a fórmula do "conhece-te a ti mesmo (gnôthi seautón) evoca, portanto, uma prática de si que não implica apenas numa consciência racional que conheça os códigos morais, mas numa apropriação desses códigos a partir de uma ascese. É

\footnotetext{
${ }^{7}$ Foucault, ao citar o filósofo romano Apuleu destaca, todavia, que no período clássico circulava a ideia de que "aperfeiçoar a própria alma com a ajuda da razão [é uma regra] igualmente necessária para todos os homens" (FOUCAULT, 2014b, p. 62).
} 
oportuno lembrar que foi esse tipo de questão, sobre o autoconhecimento, que Platão elaborou no diálogo entre Ménon e Sócrates. Mênon indagava Sócrates: "Mas de que modo buscarás, Sócrates, aquilo que absolutamente ignorais?”. Ao passo que Sócrates afirmava que só os corajosos não se cansam de procurar (PLATÃO, 2001, p. 53).

Em Alcibíades, Platão conduz o protagonista do diálogo ao entendimento de que buscar saber-se requer coragem na procura do cuidado de si, e diz Sócrates:

Bem, Alcibíades, [conhecer a si mesmo] pode ser fácil ou não, mas para nós o problema se coloca assim: se conhecermos a nós mesmos, também conheceremos, talvez, os cuidados que devemos ter para conosco; senão, não os conheceremos jamais. (PLATÃO apud NICOLA, 2005, p. 54, grifosnossos).

Ao analisar a formação do sujeito e sua relação com a verdade, entre os antigos gregos, Foucault chama atenção para o diálogo entre Sócrates e Alcibíades cuja hermenêutica se estabelece sobre a dupla necessidade de um cuidado consigo mesmo por parte do interlocutor de Sócrates. Foucault aponta que "a necessidade de cuidar de si está vinculado ao exercício do poder”, em outras palavras, refere-se não apenas ao cuidado consigo, mas também com os outros; e em segundo lugar, "a necessidade do cuidado de si inscreve-se pois, não somente no interior do projeto político, mas também no interior do déficit pedagógico", isto é, sua importância está tanto para as relações intersubjetivas de poder quanto nas relações intersubjetivas de aprimoramento do saber, sem o prejuízo da ordem desses aspectos.

Foucault destaca ainda que, a despeito do que Sócrates afirmara, em outro diálogo (Apologia de Sócrates), onde cuidado de si aparece como uma "função geral de toda a existência", em Alcibíades, todavia, aparece como um "momento necessário" na constituição do sujeito em formação. Em suma, diz Foucault:

[...] o que está em jogo em toda a segunda parte, neste final do diálogo, é a necessidade de fornecer a esse 'si mesmo' - na expressão 'cuidado de si mesmo' uma definição capaz de aplicar, abrir ou dar acesso ao saber necessário para um bom governo. [...] qual o eu de que devo ocupar-me a fim de poder, como convém, ocupar-me com os outros a quem devo governar. (FOUCAULT, 2010., p. 36).

Portanto, nesse ponto, segundo Foucault, apresenta-se uma questão fundamental na filosofia socrática-platônica que é a busca por respostas acerca do si mesmo e, mais que isso, buscar conhecer a tékhne (técnica) necessária para saber governar-se e governar os demais. Assim, o conhecimento de si, vinculado ao cuidado de si, possibilita o governo de si e dos 
outros, estabelecendo, então, laços sociais e referências aos ideais éticos ${ }^{8}$. O que não significa dizer que se trata de mera sujeição do sujeito a um código moral, mas, ao contrário, há um refazimento do que é coletivo, então, político, a partir do sujeito e sua subjetivação, portanto, ético, através da técnica do cuidado de si articulado ao conhecimento de si.

\section{A CONSTITUIÇÃO DO SUJEITO ÉTICO}

Desde o curso ministrado no College de France, em 1980, Foucault "persegue seu trabalho de genealogista da subjetividade ocidental" tornando o cristianismo primitivo o seu objeto de estudo, buscando compreender três instituições em particular: o batismo, a penitência e a direção da consciência. (MANICKI, 2012, p. 57).

Foucault propõe num de seus deslocamentos teóricos, deixar em suspenso o debate sobre o sujeito e sua relação com o saber e o poder, para investigar a relação do sujeito com a verdade, apresentando como chave de leitura a noção de cuidado de si, como técnicas a serem apropriadas pelo sujeito na compreensão do próprio sujeito em "ser sujeito", na história como um todo. Diz ele:

Parece-me que a aposta, o desafio que toda história do pensamento deve suscitar, está precisamente em apreender o momento em que um fenômeno cultural, de dimensão determinada, pode efetivamente constituir, na história do pensamento, um momento decisivo no qual se acha comprometido até mesmo nosso modo de ser de sujeito moderno. (FOUCAULT, 2010, p. 11)

Tal incursão filosófica faz uma revisão dos clássicos da antiguidade helênica e cristã. Aprofunda as releituras socrático-platônica, helênica-romana e cristã, e demonstra como o sujeito foi sendo construído enquanto representação e discurso, na história, mediante a cultura.

Nesse sentido, Díaz (2012) organiza os elementos constitutivos da subjetividade moral, apresentados por Foucault (2010; 2014b), que, de certa maneira, afirma Díaz (ibidem, p. 172) "[são] como dobras do fora que se introduzem no dentro". Assim, constituem a subjetividade:

\footnotetext{
${ }^{8}$ Confira o Capítulo III, "Eu e os outros" da História da Sexualidade III: cuidado de si (Foucault, 2014c, p. 94 126). 
Quadro 1: Elementos constitutivos da subjetividade moral em Foucault.

\begin{tabular}{|l|r|r|r|}
\hline & \multicolumn{1}{|c|}{ GREGOS } & ESTOICOS/ ROMANAOS & \multicolumn{1}{c|}{ CRISTÃOS } \\
\hline Substância: & $\begin{array}{r}\text { Força que conduz o uso dos } \\
\text { prazeres }\end{array}$ & $\begin{array}{r}\text { A mesma força, mas se indica sua } \\
\text { fragilidade }\end{array}$ & $\begin{array}{r}\text { Desejo, concupiscência, } \\
\text { carne }\end{array}$ \\
\hline Sujeição: & Estética e comunitária & Natureza, lei racional & Lei divina \\
\hline Trabalho: & Ascética, relações políticas & Ascética, autodomínio & Ascética, auto-decifração \\
\hline Telos: & Liberdade e verdade & Impertubabilidade do ânimo & Salvação da alma \\
\hline
\end{tabular}

Fonte: Díaz (2012, p. 172).

Como é possível visualizar no quadro 1, acima, o estudo genealógico de Foucault busca compreender o que é e o que se vem entendendo por sujeito ao longo da história ocidental, não necessariamente em seu significado ontológico de um passado distante, mas suas formas conceituais no presente, importando a relação entre sujeito e verdade.Quiçá, a sua verdade. Nesse sentido, segundo Cesar Candiotto, Foucault privilegia a "prática da direção de consciência" como trabalho na constituição do sujeito ético, entretanto adverte:

[...] Foucault não está interessado na doutrina ou teoria do estoicismo ou sua função na instituição do Império romano; muito menos, constituem seus objetos de análise as doutrinas, as crenças e representações religiosas do cristianismo. [...] Sua análise enfatiza as relações de poder e suas técnicas que atravessam essas instituições, perpassam os indivíduos nelas concernidos e proporcionam efeitos de positividade. Positividade aqui no sentido de produção, de fabricação, de constituição de algo como problemático para o pensamento. (CANDIOTTO, 2012, p. 93, grifos do autor).

Sua intenção, portanto, não é fazer teologia cristã, mas saber quais as razões que desconsideraram a noção de epiméleia heautoû (cuidado de si) como pensamento, na história da filosofia. E é por isso que o filósofo de Poitiers persegue a ideia de que há algo perturbador no princípio do "cuidado de si" e que justamente por isso apresenta-se a urgência de retomálo como princípio de criatividade artística, porque para o autor, a vida de cada indivíduo é uma "obra de arte" (FOUCAULT, 1994, p. 350) ${ }^{9}$.

O cuidado de si (epimeleia) é um verdadeiro labor, uma prática, um exercício que se assemelha às atividades do dono da casa, aos compromissos de um príncipe no zelo por seus súditos, aos cuidados com um doente ou ferido, ou às obrigações com os deuses. $\mathrm{O}$ cuidado de si compreende etapas como num exercício de superações: a) a provação - abstinência do supérfluo; b) o exame de consciência - o que não leva a sentenças de culpabilidade ou a

\footnotetext{
${ }^{9}$ A esse respeito confira o capítulo VI, “A vida assumida como obra de arte”, de Díaz (2012, p. 209-217). 
decisões de autopunição; c) pensamento sobre o pensamento - a exemplo da metáfora do vigia noturno. (FOUCAULT, 2014c).

Dessa maneira, o sujeito se constitui de autocontrole, de governabilidade de si. A esse respeito diz Foucault (Ibidem, p. 82, grifo nosso): "O controle é uma prova de poder e uma garantia de liberdade: uma forma de assegurar-se permanentemente de que não nos ligaremos ao que não depende do nosso domínio". O desbaratamento do trabalho ético na constituição do sujeito, isto é, a reconfiguração sucessiva do lugar onde, na antiguidade, ocorria a relação entre ética e conhecimento ${ }^{10}$, tende a dificultar a subjetivação. Nesse sentido diz Foucault:

Com o cristianismo, veio a se instaurar lentamente, progressivamente uma mudança em relação às morais antigas, que eram, essencialmente, uma prática, um estilo de liberdade. [...] a vontade de ser um sujeito moral e a procura de uma ética da existência era principalmente, na Antiguidade, um esforço para afirmar a própria liberdade e dar a sua própria vida uma certa forma na qual podia se reconhecer e ser reconhecido por outros e onde a posteridade mesma poderia encontrar como exemplo [...] Da Antiguidade ao cristianismo, passou-se de uma moral que era essencialmente uma busca de uma ética pessoal a uma moral como obediência a um sistema de regras.

Todavia, é importante destacar que para Foucault, a subjetivação, portanto,

“[...] não é [...] objeto de uma prescrição resultante de um código de conduta ou de um regulamento que busca absolutamente organizar o comportamento dos indivíduos [...] não significa também a aceitação estrita de uma moral, mas uma aceitação livre de um modo de vida, de uma conduta ou até mesmo de um hábito" (BERT, 2013, p. 172).

A técnica do cuidado de si, sob a prática da espiritualidade, originária entre os helênicos, continuada pelos cristãos nos primeiros séculos medievos, conduzem a consciência do sujeito moral a compreender que ele precisa refazer-se, desaprender-se das determinações de sistemas morais e reaprender-se consigo mesmo. Ocupar-se consigo.

\section{CONCLUSÃO}

[...] olhar na direção da luz, não apenas [...] lhe causaria dor, como também o deslumbramento o impediria de ver os objetos cujas sombras até então ele enxergava. (PLATÃO, 2000, p. 320).

\footnotetext{
${ }^{10} \mathrm{Na}$ classificação dos constituintes do sujeito, Deleuze propõe a comparação dos elementos foucaultianos às quatro causas aristotélicas na formação do ser. Confira Deleuze, 1991, p. 111-2 e Díaz, 2012, p. 173.
} 
Hannah Arendt corrobora que mesmo em tempos sombrios temos o "direito de esperar alguma iluminação" (ARENDT, 2008, p. 9), ainda que da efêmera existência de algumas pessoas que resistem em manter seu brilho, pessoas que certamente cuidaram e cuidam de si. Zigmunt Bauman insiste em afirmar que a frustração e as incertezas possibilitam ao sujeito que se busca moralmente, "permanecer pessoa moral", porque "a responsabilidade moral é a mais pessoal e inalienável das posses humanas, e o mais precioso dos direitos humanos". (BAUMAN, 1997, p. 285).

Dessa maneira, a constituição ontológica do sujeito perfaz um percurso histórico da sujeição, ou seja, a determinação do sujeito pelos regimes de poder, de saber e de verdade a que esse sujeito fora submetido. Dito de outro modo, o sujeito se fez a partir dos códigos morais estabelecidos pela cultura a que fez parte ao longo da história.

Apesar disso, importa perceber o sujeito que se constitui enquanto relação com a verdade, isto é, através do cuidado de si, desenvolvendo técnicas no aperfeiçoamento da subjetividade. É desse modo que o sujeito se auto-constitui pela subjetivação, pela "estética da existência".

O sujeito ético depende de uma prática de si a despeito dos códigos morais que o constitui. O sujeito se faz no cultivar-se constante buscando conhecer-se e conhecer o outro, buscando cuidar de si e dos outros. O sujeito é ético à medida que se ocupa de si, passa a conhecer-se, possibilitando o governo de si e dos outros, estabelecendo, então, laços sociais, desenvolvendo condutas éticas, a despeito dos tempos serem sombrios ou iluminados, no Brasil ou em qualquer lugar do planeta.

O sujeito ético não teme o niilismo ético porque compreende que a história e a cultura são modificáveis, são transformáveis e indefinidas. O sujeito ético também não se deixa cair no individualismo autista, isto é, não se fecha sobre si, não se nega e nem foge do seu trabalho de pensar-se, cuidar-se e de conhecer-se.

Portanto, com a noção de "cuidado de si", redescoberta e estudada por M. Foucault, é possível compreender e interpretar o sujeito ético enquanto subjetivação, isto é, um sujeito reelaborado por si mesmo, que se pensa e se faz, desfaz-se e se refaz, constrói-se, cria-se, mesmo diante de sujeições morais ao longo da história, ou mesmo pela falta de referência de códigos morais, de uma ausência de moralidade para constituí-lo. O sujeito, ao cuidar de si e ao buscar conhecer-se, tende a sair das sombras de seu tempo, deixa a obscuridade da existência e assume a responsabilidade do equilíbrio pendular entre a sua interioridade, 
constituída pelo desejo de liberdade numa reflexão contínua sobre esse desejo, e sua exterioridade, na busca pela segurança entre si e os outros, na reflexão constante sobre os códigos que a história e a cultura constituem-no. Torna-se sujeito ético. Em tempos sombrios haverá sempre a necessidade da luminosidade do sujeito ético.

\section{REFERÊNCIAS}

ARENDT, Hannah. Homens em tempos sombrios. Tradução Denise Bottmann. São Paulo: Companhia de Bolso, 2008.

BERT, Jean-François. Pensar como Michel Foucault. Tradução Marcos Marcionilo. São Paulo: Parábola, 2013.

BAUMAN, Zygmunt. Comunidade: a busca por segurança no mundo atual. Tradução Plínio Dentzien. Rio de Janeiro: Zahar, 2003. Modernidade líquida. Rio de Janeiro: Jorge Zahar, 2001 . Ética pós-moderna. Tradução João Rezende Costa. São Paulo: Paulus, 1997.

CANDIOTTO, Cesar. A prática da direção de consciência em Foucault: da vida filosófica à vida monástica cristã. In: CANDIOTTO, Cesar; SOUZA, Pedro de (org.). Foucault e cristianismo. Belo Horizonte: Autêntica Editora, 2012, p. 93-110. (Coleção Estudos Foucaultianos, 10).

CASTRO, Edgardo. Introdução a Foucault. Tradução Beatriz de Almeida Magalhães. Belo Horizonte: Autêntica, 2014.

CHADE, Jamil. Partidos são 'corruptos ou muito corruptos' para $81 \%$ dos brasileiros. O Estado de São Paulo, São Paulo, 08 jul. 2013. Disponível em: http://politica.estadao.com.br/noticias/geral,partidossao-corruptos-ou-muito-corruptos-para-81-dos-brasileiros,1051458 . Acesso em 18/04/2018.

DATAFOLHA. Opinião pública. São Paulo, 26 jun. 2017. Disponível em: http://datafolha.folha.uol.com.br/opiniaopublica/2017/06/1896245-92-acreditam-que-justica-tratamelhor-os-ricos-do-que-os-pobres.shtml . Acesso em: 18/04/2018

DELEUZE, G. Foucault. São Paulo: Brasiliense, 1991.

DÍAZ, Esther. A filosofia de Michel Foucault. Tradução Cesar Candiotto. São Paulo: UNESP, 2012.

FOUCAULT, M. A hermenêutica do sujeito (1981-1982). Tradução Márcio Alves da Fonseca e Salma Tannus Muchail. 3 ed. São Paulo: WMF Martin Fontes, 2010. (Coleção Obras de Michel Foucault)

Da amizade como modo de vida: uma estética da existência. Une esthétique de l'existence (entretien avec A. Fontana), Tradução Wanderson Flor do Nascimento. Le monde, 15-16 juillet 1984, p. XI. Disponível em: http://files.philoethos.webnode.pt/200000086-4b9ae4bf4e/estetica.pdf. Acesso em: 06/04/18.

História da sexualidade 3: o cuidado de si. Tradução Maria Thereza da Costa Albuquerque. São Paulo: Paz e Terra, 2014a. 
História da sexualidade 2: o uso dos prazeres. Tradução Maria Thereza da Costa Albuquerque. São Paulo: Paz e Terra, 2014b.

Dits et écrits, VI. Paris: Gallimard, 1994.

Verdade e subjetividade, p. 205 in. Revista de Comunicação e Linguagens, $\mathrm{n}^{\circ}$ 19. Tradução

Antônio Fernando Cascais. Lisboa: Cosmos, 1993.

. Sexualité et solitude. In DE II, p. 989 Dits et écrits II. Paris: Gallimard, 2001.

MANICKI, Anthony. Técnicas de si e subjetivação no cristianismo primitivo:uma leitura do curso Do governo dos vivos. In: CANDIOTTO, Cesar; SOUZA, Pedro de (org.). Foucault e cristianismo. Belo Horizonte: Autêntica Editora, 2012, p. 57-72. (Coleção Estudos Foucaultianos, 10).

NICOLA, Ubaldo. Antologia ilustrada de filosofia: das origens à idade moderna. Tradução Maria Margherita De Luca. São Paulo: Globo, 2005.

O LIBERAL. Reprovação de Temer é de 70\%. Caderno O poder, p. 2, Belém, 18 abr. 2018.

OLIVEIRA, Cláudia Maria Rocha de. À sombra da ruptura: niilismo ético e filosofia na era das incertezas. Sapere Aude. Belo Horizonte, v. 6 - n. 12, p. 816-831, Jul./Dez. 2015 - ISSN: 2177-6342. Disponível em: http://periodicos.pucminas.br/index.php/SapereAude/article/view/11252/9107 . Acesso em 20/abr/2018.

PLATÃO. Mênon. Texto estabelecido e anotado por John Burnet. Tradução Maura Iglésia. Rio de Janeiro: PUC-Rio; São Paulo: Loyola, 2001.

2000.

. A República, Livro VII, 515, Ic. Tradução Carlos Alberto Nunes, 3. ed. Belém: EDUFPA, 